\title{
Challenges of Blended Learning in Refugee Camps: When Internet Connectivity Fails, Human Connection Succeeds
}

Mohamed Aziz Dridi' ${ }^{1}$ Dhinesh Radhakrishnan', Barbara Moser-Mercer², and Jennifer DeBoer1

${ }^{1}$ School of Engineering Education, Purdue University, USA, ${ }^{2}$ InZone, University of Geneva, Switzerland

\begin{abstract}
In this paper, we studied the implementation of a course on global history as a blended section of a massive open online course (MOOC) and the learning challenges faced by the students in three crisis contexts: Azraq refugee camp (Jordan), Kakuma refugee camp (Kenya), and Amman urban refugee center (Jordan). The results showed that poor Internet connection in the camps severely impacted both students' and instructors' experience of the course. In the context of chronic Internet connectivity issues, the instructors had difficulties assessing their students' needs and challenges. The results also showed that in light of these intermittent connection problems, the collaborative learning environment helped students navigate the challenges of a blended course. Also, the onsite visit by the online tutors and the face-to-face interactions that resulted from it had a noticeable impact on the human dynamics of the course by allowing instructors to provide targeted solutions to students' problems as well as by building rapport between the students and the instructional team.
\end{abstract}

Keywords: massive open online course, MOOC, refugees, education in emergencies, blended learning, collaborative learning 


\section{Introduction}

By the end of 2018, more than 74.8 million people had been forcibly displaced worldwide as a result of persecution, wars, violence, or human rights violations (United Nations High Commissioner for Refugees [UNHCR], 2018). Almost one-third of displaced people are currently under the United Nations Higher Commissioner for Refugees' mandate, and $85 \%$ are hosted by countries in low-resource regions, with the least developed countries providing shelter for $26 \%$ of the total refugee population (UNHCR, 2018).

In this fragile context, education provision is a complex but pressing issue. While access to education is a human right enshrined in Article 26.2 of the Universal Declaration of Human Rights (The United Nations, 1948), only a tiny minority of refugee youth can access higher education (UNHCR, 2016a). The other $99 \%$ makes up a lost generation of young people with no or inadequate access to higher education. As stated in the Framework for Action Education 2030, published by the United Nations Educational, Scientific, and Cultural Organization (UNESCO), "the failure to prioritize education in humanitarian response renders entire generations uneducated, disadvantaged and unprepared to contribute to the social and economic recovery of their country or region" (UNESCO, 2015, p. 5).

Similar to other migrant groups, refugees have strong aspirations for education as a proactive response to their past persecutions and travails (Stevenson \& Willott, 2007). Cross-national research has demonstrated that education supports the development of innovation and entrepreneurial skills that are essential for employment and economic activity (Hanushek \& Woessmann, 2007). When offered a high-quality education during their exile, refugees increase their chances of economic and, thus, social integration in their host country upon resettlement or repatriation. Humanitarian organizations have, therefore, increasingly adopted a rights-based approach to education and have drawn attention to the link of education and protection. Thus, in 2010, UNHCR's education unit was moved from the Division of Operational Support to the Division of Protection, showing its importance as an immediate right for refugees. More recently, it was moved to the Division of Resilience and Solutions, reflecting a notable shift in considering education as a long-term development imperative rather than an immediate operational emergency.

Traditionally, education in emergencies has prioritized primary education. Current trends show that over $61 \%$ of refugee children access primary education, $23 \%$ secondary education (UNHCR, 2018), and only an estimated $1 \%$ access higher education (UNHCR, 2016a). The small share of higher education in emergencies finds its origin in the 1951 convention relating to the status of refugees, which obliges host countries to provide primary and secondary education to refugees but remains silent on higher education. In the absence of a binding legal framework, infrastructural problems, inherent to any refugee context, are amplified and make any educational interventions particularly challenging.

In this research, we studied the implementation of a blended learning course in a situation of crisis and poor telecommunication infrastructure and focused on the role of face-to-face interactions as well as collaborative learning. We begin by providing background literature and describe how we collected and analyzed the data to support the findings of this study. We then present the themes that emerged from the data analysis before discussing them in detail. 


\section{Background}

\section{Blended Learning for Higher Education in Emergencies}

Blended learning, according to the Innosight Institute, is a formal education program in which a student learns at least in part through online delivery of content and instruction with some element of student control over time, place, path, and pace (Staker \& Horn, 2012). Schools all around the world are increasingly using a blended learning model across all grade levels (Zaka, 2013). Access to technology has leveraged opportunities to integrate the best online activities into instruction. Schools in highincome countries are using blended learning models to expand their course offerings (Means, Toyama, Murphy, \& Bakia, 2013). Blended learning has been shown to be beneficial for a number of student outcomes beyond solely online or solely face-to-face instruction, because of its potential to provide flexible access to content and instruction at any particular time, from any place (Means et al., 2010). As well, if its affordances are realized, blended learning can be tailored to student needs. In the book Learning Online, Means (2014) listed the following purposes for blending instruction:

- Broadening access to instruction.

- Facilitating small-group and one-to-one teacher-led instruction.

- Serving students with very diverse needs.

- Providing more opportunity for productive practice.

- Adding variety to teaching and enhancing student engagement.

- Supporting the learning of complex, abstract concepts.

Considering the potential benefit of all the goals mentioned above, as well as the research on blended learning's effectiveness, blended learning qualifies as a potentially effective pedagogical tool for higher education in emergencies. Through blended learning, academic institutions can bring cutting-edge programs to remote contexts via online technology, while also providing personalized and focused instructional support through local tutors.

In low-resource contexts, blended learning models can be an alternative to schooling in situations where movement is restricted or where educational infrastructure is weak or nonexistent. Despite the purported use of blended learning models to enhance access to education, there is little information on how they can be better adapted to the specific needs and challenges faced by refugees in fragile contexts. However, some parallels could be drawn from previous experiences of implementing MOOCs in developing countries. In fact, in these settings, computer-aided learning has sometimes presented severe limitations in terms of both instructional design and field classroom implementation. For example, Wildavsky (2017) pointed out that finding the most appropriate technology when implementing MOOCs in Africa is a challenge. The authors echoed previous studies highlighting that broadband Internet connections are often hard to access, making mobile phones the best way to reach some students in low-income countries. The issue of Internet connectivity in low-resource countries has pushed MOOC designers to revisit the course elements in light of limited bandwidth. For instance, Murugesan, Nobes, and Wild (2017) studied an online course in research writing offered in a massive open online course (MOOC) format for developing country researchers. In this case, MOOC designers 
intentionally developed low-bandwidth instructional elements in order to take into consideration the limitation of computer-aided learning in low-resource locations. In addition, Moser-Mercer's (2014) study of a MOOC in Dadaab refugee camp in Kenya also called for the need to consider offering suitable engagement tools for students specific to the particular infrastructural challenges encountered in refugee camps.

Some of the challenges associated with implementing blended learning courses in fragile contexts are inherent to computer-supported learning. In fact, this type of learning requires a shift from traditional teaching practices to a new type of instruction where teachers are aware of the limitations and challenges inherent to technology implementation and can take advantage of the particular affordances of the technology only where it makes sense. Notably, using computers can also change the arrangement of classrooms, the social organization of student learning, and the interactive patterns between teachers and students (Duffield et al., 1999). The reconfiguration of the teaching space, as a direct consequence of computer-supported learning, motivates part of our research goal in studying the way educational technology interacts with the social dimension of the classroom in crisis-affected contexts.

This paper attempted to reach the research goal mentioned above by exploring the case of a massive open online course (MOOC) on global history, called Global History Lab (GHL), offered on the edX platform, that was implemented in two refugee camps in Jordan and Kenya and an urban refugee space in Jordan. This MOOC was a blended learning course resulting from a collaboration between Princeton University and InZone, an academic center at the University of Geneva.

\section{Context}

\section{MOOCs}

As massive open online courses (MOOCs) became a broadly recognized higher education phenomenon (Breslow et al., 2013), education researchers and students alike quickly realized that the spectrum of MOOC classes was broad and diverse. For example, the earliest use of the MOOC term was applied to what became known as cMOOCs, as early as 2008, where the letter "c" stands for connectivist; these MOOCs grew up from a set of diffuse courses and course materials that centered learners and their communication together to co-construct knowledge (Joksimovic et al., 2015). On the other hand, more recent MOOCs like xMOOCs, grown out of the artificial intelligence academic community, focused on automated response systems to give students immediate feedback and other intelligent tutoring systems mechanisms. In both cases, instructors, students, and researchers have had to navigate a rethinking of familiar educational constructs from face-to-face or distance learning that the MOOC classes expanded or upended (DeBoer, Ho, Stump, \& Breslow, 2014). In the class we studied in this article, we identified elements such as student-to-student connection and online lecture recording-derived from aspects of both xMOOCs and cMOOCs-applied in a complex and novel structure, context, and pedagogy.

\section{Course Description}

In this article, we studied the case of the Global History Lab (GHL), a 16-week blended learning course on global history implemented in three refugees settings. GHL was originally develooped as a MOOC by Princeton University and offered on the edX MOOC provider platform. The course studied in this 
article was an adapted version of the eponym designed by Princeton University in collaboration with InZone, University of Geneva. Following the recommendations of a pilot study on the implementation of MOOCs in fragile contexts (Moser-Mercer, 2014), the adapted version of GHL included different assignments and pacing in order to take into consideration the particular context of refugee camps. The course integrated 19 learners in the Kakuma Camp in Kenya, 10 in the Azraq Camp in Jordan, and a cluster of 3 refugees from Syria and 2 Jordanians in urban Amman. As shown in Table 1, different actors and institutions constituted the learning ecosystem of the GHL course.

Table 1

The GHL Course Learning Ecosystem

\begin{tabular}{|c|c|c|}
\hline Actor & Affiliation & Role \\
\hline Lecturer & Princeton University & $\begin{array}{l}\text { Provide course material } \\
\text { Encourage knowledge generation } \\
\text { Evaluate and grade assignments }\end{array}$ \\
\hline Course coordinator & InZone Geneva campus & $\begin{array}{l}\text { Liaise among the ecosystem's actors } \\
\text { Manage and monitor the pedagogical } \\
\text { set-up and implementation } \\
\text { Deal with administrative matters }\end{array}$ \\
\hline Online tutors & Princeton University & $\begin{array}{l}\text { Stimulate knowledge acquisition } \\
\text { Support and advise learners } \\
\text { Encourage group discussion }\end{array}$ \\
\hline Onsite facilitators & InZone Kakuma campus & $\begin{array}{l}\text { Provide technical support } \\
\text { Support students in their learning } \\
\text { experience } \\
\text { Liaise among learners and other } \\
\text { actors } \\
\text { Coordinate onsite cooperative learning }\end{array}$ \\
\hline Students & $\begin{array}{l}\text { Azraq refugee camp } \\
\text { (Jordan) } \\
\text { Amman urban refugee } \\
\text { center (Jordan) } \\
\text { Kakuma refugee camp } \\
\text { (Kenya) }\end{array}$ & $\begin{array}{l}\text { Engage with course activities and } \\
\text { other students with the goal of } \\
\text { achieving course learning outcomes }\end{array}$ \\
\hline
\end{tabular}

The course consisted of two, one-hour lectures each week that the students accessed via the edX platform. The students were provided with a textbook (both a physical and a digital copy on a USB drive) that contained 12 case studies. The 12 case studies covered pressing themes in global history with a particular focus on the history of migration and statelessness. Those case studies constituted the course's bi-weekly assignments where students were asked to work in teams under the supervision of an onsite facilitator. The onsite facilitator's role was to ensure students' access to the learning hub in each camp and to liaise with the online tutors. The online tutors' role consisted of engaging with the students after they had watched the online lectures to make sure they understood the content. They interacted with the students via a WhatsApp forum in the three locations. Throughout the course, students met face-to-face with each other and with local onsite facilitators multiple times per week to review online materials together and work through assignments. In the middle of the GHL course, the online tutors made an onsite visit to the three locations where they met and interacted with the students 
for the first time. The meetings at the learning hubs, together with onsite visits from online tutors, formed the face-to-face component of the blended course.

With particular regard to conflict-sensitive education, the Global History Lab course complied with the Inter-Agency Network for Education in Emergencies (INEE) Minimum Standards for education in emergencies (INEE, 2010). In addition, the course complied with humanitarian principles, particularly that of "Do no harm" as enshrined in international humanitarian law, as well as directives and recommendations on diversity and inclusiveness, prevention of gender-based violence, and so on.

\section{Methodology}

\section{Purpose}

The purpose of this study was to investigate the limitations faced when implementing a blended learning environment in fragile contexts where technological infrastructure remains deficient. Specifically, this study addressed the research question: What components of the GHL course design impacted the students' and instructors' experience of the course? Our research question allowed for a careful analysis of learners' needs, a critical step toward the development of context-appropriate solutions that go hand-in-hand with leveraging informal education offerings in fragile contexts.

\section{Data Collection}

As shown in Table 2, our study considered several data sources. These data consisted of (a) tri-weekly reports from online tutors and onsite facilitators, (b) learning community narratives, and (c) WhatsApp conversations. Also, we conducted focus group sessions with the students in order to elicit supplemental data regarding collaborative learning and the use of technology for the three learning sites.

Table 2

Data Sources and Types

\begin{tabular}{ll}
\hline \multicolumn{1}{c}{ Data source } & \multicolumn{1}{c}{ Data type } \\
\hline Online tutors & $\begin{array}{l}\text { Tri-weekly report } \\
\text { Learning community narrative } \\
\text { WhatsApp conversations }\end{array}$ \\
Onsite facilitators & Tri-weekly report \\
& Learning community narrative \\
& WhatsApp conversations \\
& Weekly report \\
Learners & Learner narrative mid-term \\
& Learner monthly narrative \\
& WhatsApp conversations \\
\hline
\end{tabular}




\section{Data Analysis}

In this study, we performed a thematic analysis on available data sources using NVivo software to identify, organize, and develop insights into patterns of meaning (themes) across the data sets. We adopted a five-phase approach in performing the thematic analysis. The five phases, sequentially, were: a) familiarization with the data, b) generate codes, c) search for themes, d) review potential themes, and e) define themes. We chose as a unit of analysis the respondent role in the learning ecosystem. Essentially, before coding that data, we grouped the respondents and their responses into three different categories: students, onsite facilitators, and online tutors. A first pass of open coding was performed on the three units of analysis that led to 59 emergent codes. Following this, the researchers conducted axial coding in order to relate the initial codes to each other in light of the research question. From this step, we identified three themes that aligned with our research question. After identifying the themes that emerged from the data under each code, a final analysis was done to check for overlapping themes across the different codes. To ensure coding reliability, we followed Syed and Nelson's (2015) reconcile differences via consensus method. Following this approach, two members of the research team coded all of the data, then discussed any discrepancies in the coding and resolved them through consensus to ensure inter-coder reliability.

\section{Results}

When we explored the components of the course design that impacted the students' and instructors' experience of the course, our data analysis revealed three main themes. These are described in detail below.

\section{Theme 1: Connectivity/Internet Issues}

Persistent and recurrent Internet connectivity problems emerged as a salient challenge faced by students and instructors. Interestingly, these problems were noticeable in all three sites, whether due to poor telecommunication infrastructure in remote locations (i.e., the two refugee camps) or to lowerbandwidth services available to students in the urban center. In all three sites, both online tutors and students reported connectivity to be a significant issue. An online tutor recounted, "WhatsApp tutoring has severe limitations, and learners clearly liked to see my face (Skype or other platforms), but poor connection and hardware problems made this problematic." Furthermore, when asked what they would like to change about the learning space in the three sites, many students cited Internet connection as a major point to address. The issue of Internet connectivity was challenging not only for the students but also for the online tutors. As noted by one of the online tutors from the Kakuma refugee camp (Kenya):

Students also voice considerable frustration at the often-problematic Internet connectivity. Six out of 19 have access to their own computers and can make use of the USBs, while the rest still [use] the USBs from the InZone's Hub. Students only go online to post, comment, report on other case studies, or check their e-mails (most irregularly).

In fact, from the online tutors' perspective, the intermittent connection problems made them feel powerless to help their students engage in the class discussions. As one of them said, "it is demoralizing when students can no longer post because they did not have an Internet connection to do so on time." One interesting feature to note was how online tutors (who worked at a distance) and onsite facilitators (who were based in the camp/urban setting and interacted face-to-face with learners) perceived the 
issue of poor Internet connection differently and how it impacted students during the online global history course. Online tutors did not raise the issue of poor Internet connection until their field visit, even though some students reported technical difficulties as one reason they reached out to their online tutors. On the other hand, onsite facilitators consistently reported poor Internet/network connectivity as being a challenge for the students. This finding suggests that due to difficulties in communicating with students, online tutors' perception of the students' needs and learning experience were initially inaccurate. The finding also reinforced the idea of how important the role of local facilitators can be.

\section{Theme 2: Teamwork}

Teamwork emerged as a salient theme across the data sets, as students expressed their reliance on collaborative work and how helpful it was to work with their peers. For instance, a student from Kakuma described the collaborative learning sessions and the relative importance of teamwork above other learning activities as follows.

You improve your understanding during discussions, discussions are more important than the readings, we wish we had 2-3 days for discussions, readings were often boring, it was hard to concentrate, videos were difficult to download, the online tutor was helpful, it was important to learn from the group, in little time you learn a lot and you can share responsibilities, summaries really help you understand concepts.

Another student was asked if he would get the same learning benefits if the team were online instead of local to which he replied, "no, of course not; there would not be the same focus and we would miss out on the interaction. We don't believe in communicating online; it is very different." Inadequate Internet infrastructure, as noted in our findings, impacted the students' perception of the course. Also, teamwork constituted an important resource that the students leveraged during a course where the online component was challenged because of connectivity issues. As one of them reported, "group work is the feature that students and local tutors reported as real benefit of this course."

\section{Theme 3: Field Visit of the Online Tutors to the Students Impacted Tutors' Perception of the Course}

As noted previously, online tutors' perceptions of connectivity issues changed after their onsite visit. More broadly, we found in response to our research question that the online tutors' visit changed their perception of the students' difficulties at pedagogical as well as technical levels. It was an opportunity for them to hear from the students themselves about their concerns. Further, online tutors were able to work more directly with students on both study skills and course content, perceiving the face-to-face interaction as more efficient than their previous online tutoring support. As one online tutor reported, "I was able to spend three half-days with them and I believe we made significant headway in terms of tangible skills like time management, reading and comprehension, and techniques at the heart of the global history lab.”

Also, the onsite visit had the online tutors recalibrate their supporting strategy by helping the students identify successful resource-seeking behaviors. As one online tutor noticed:

The workshop we facilitated in person about the final assignment was one of our most successful and helpful interactions with the students. We proved to the students that by reading the documents they had all the answers they needed to work on their assignment, without having to consult the Internet or other more dubious sources. 
Furthermore, the onsite visit allowed the online tutors to have a better picture of the issues related to connectivity and how they could address these along with the onsite facilitators. "It made it a lot easier to get down to brass tacks with [onsite facilitators] about the students' connectivity issues, research documents, and coursework." Another online tutor noted:

Their access to the Internet appears to have been much more limited than I think we understood in the first month or so of the course before [onsite facilitators joined as a more regular point person in Azraq].

The onsite visit not only changed the online tutors' perceptions, but it shifted their pedagogical approach and, by extension, the dynamics of the course. As a matter of fact, after their visit, the online tutors opted for printing the online documents and ensured they were handed out to the students to get around connectivity problems. As one online tutor explained:

We are also making my weekly update e-mails as well as the transcripts of the lectures available in print copy to facilitate students' independence from Internet connectivity. One thing to take away is that printed out transcripts should also be provided from the start for the Kakuma learners in the future as for the majority, English is not their first language.

\section{Discussion}

Issues of Internet connectivity altered the students' experience during the GHL course and compromised the planned online component of the blended-learning design of GHL. In fact, intermittent Internet interruption resulted in delayed communication between students and instructors. Delay in communication is one weakness of online learning that is reported by many researchers (Howland \& Moore, 2002; Petrides, 2002; Vonderwell, 2003). According to the study by Howland and Moore (2002), the communication between students and instructor was a critical issue. Students felt less confident in guidance when the feedback from their instructor was delayed. In addition, in Howland and Moore's study, the authors found that many students reported that it was difficult to get clarification on assignments, and other issues, due to lack of communication between student and instructor.

In their systematic literature review of the design of blended learning environments, Boelens, De Wever, \& Voet (2017) found that in those environments, face-to-face and online components were generally used for different purposes. While face-to-face components were generally designed to guide the students through the organization of the course and clarify the course's expectations, the online component was used to monitor students' learning process through formative peer and teacher assessment. In the case of the GHL course, the onsite visit was purposively seeded in the course design in order to strengthen the teacher-student relationship.

The emergent theme that reflected the impact of the onsite visit on the course dynamics shows that online tutors had a better understanding of the challenges faced by the students after the onsite visit. Furthermore, the onsite visit of the online tutors made them realize the importance of the role played by the onsite facilitators and overall, the logistical challenges inherent to education in emergency contexts. As one of them stated: 
Azraq is not a place where we can expect to "set it and forget it" with a course that has as many components (online, offline, research demands, coursework) as this. The logistics don't selfcorrect. This visit emphasized that this course needs careful stewardship both from us remotely and locally, both from the onsite facilitators as well ensuring that we have buy-in and support from our local partners.

As reflected in the online tutor's quote below, the onsite visit of the online tutors brought together the teacher and the student face-to-face and informed the teaching practice of the tutor:

There are some significant cultural differences I've encountered in the last few weeks that crystalized while I was visiting with the students. I am acquainted with the pedagogies and learning culture in Syrian higher education (more along the lines of didactic instruction and rote memorization). It wasn't initially clear how much of a challenge that this would present for the students in a course like ours that requires a shift towards thinking critically.

Our work also highlighted the intentionality required of blended learning efforts. Specifically, the online tutors' limited prior understanding and validation of the students' challenges was shaped by the on-site visit. This information was already available to the tutors, but was only reinforced when they experienced it themselves. Expanding the background information and training for online tutors would also be supported by our data. As found in previous work (Xu \& Jaggars, 2013), the social connectedness built by face-to-face interaction is important, and bringing online tutors and students together certainly improved the class because of it. Other aspects of the face-to-face connection would also be well-served by other pedagogical improvements.

\section{Conclusion}

The research design adopted for this study limits the results to the settings studied, and while some of the findings were connected to similar challenges in different settings, it is important to note that our results reflect the unique experiences of both the students and the instructors of the GHL course. In addition, the research question investigated in this study was elaborated after the data was collected which constrained the interpretation of the results.

Throughout this study, we were able to characterize the challenges faced by refugee students in fragile contexts. We were able to shed light on the limitations faced when implementing a blended learning environment in such contexts where technological infrastructure remains deficient. The results of our study highlight the importance of reconceptualizing the pedagogical and infrastructural model of MOOCs which has been shown to be necessary to achieve a more differentiated and individualized student's experience (DeBoer et al., 2014). Such reconceptualization is even more important when MOOCs are implemented in fragile settings, since most MOOC platforms are configured for course delivery to learners in highly resourced countries. For instance, issues of poor connectivity in highly resourced countries are not as prominent as in the case of a refugee camp. In such fragile contexts, poor Internet connectivity can deter students from engaging in online learning and thus reinforce their isolation.

Our findings also support the importance of collaboration in higher education in emergencies and highlight the role of onsite visits (i.e., one operationalization of instructor presence) for students. The 
impact of these concepts is stark in classrooms located in fragile settings, given the precariousness of resources for students. In such precarious settings, efficacious delivery of educational resources must take into account the need for localization to accommodate learners' particular challenges and contextual factors. As recommended by Moser-Mercer (2014), blended learning courses in fragile contexts that aspire to engage learners need to consider offering suitable engagement tools such as lower resolution versions of videos and/or podcasts of short duration, thereby facilitating the use of offline burst connectivity tools that download the minimum text-only information during connection, allow offline reading and composition of replies, and then manage upload interaction in a second burst. These tools need to be built around responsible pedagogical models that engage learners to interact with each other on the ground and allow them sufficient time to engage asynchronously with the learning material. 


\section{References}

Boelens, R., De Wever, B., \& Voet, M. (2017). Four key challenges to the design of blended learning: A systematic literature review. Educational Research Review 22, 1-18.

http://dx.doi.org/10.1016/j.edurev.2017.06.001

Breslow, L., Pritchard, D., DeBoer, J., Stump, G., Ho, A., \& Seaton, D. (2013). Studying learning in the worldwide classroom: research into edX's first MOOC. Research and Practice in Assessment, 8, 13-25. Retrieved from https://files.eric.ed.gov/fulltext/EJ1062850.pdf

DeBoer, J., Ho, A. D., Stump, G. S., \& Breslow, L. (2014). Changing "course": Reconceptualizing educational variables for massive open online courses. Educational Researcher, 34(2), 7484. https://doi.org/10.3102/0013189X14523038

Duffield, J., \& Norum, K. E. (1999). Healing the universe is an inside job: Teachers' views on integrating technology. Journal of Technology and Teacher Education, 7(3), 187-203. Retrieved from https://www.learntechlib.org/primary/p/8978/

Hanushek, E. A., \& Woessmann, L. (2007). The role of education quality for economic growth (Research Working Paper No. WPS4122). Washington, DC: The World Bank. Retrieved from http://documents.worldbank.org/curated/en/260461468324885735/The-role-of-educationquality-for-economic-growth

Howland, J. L., \& Moore, J. L. (2002). Student perceptions as distance learners in Internet-Based courses. Distance Education, 23(2), 183-195. DOI: 10.1080/0158791022000009196

Inter-Agency Network for Education in Emergencies. (2010). Minimum standards for education: Preparedness, response, recovery. USA: Inter-Agency Network for Education in Emergencies (INEE).

Joksimovic, S., Dowell, N., Poquet, O., Kovanovic, V., Gasevic, D., Dawson, S., \& Graesser, A. (2015). How do you connect? Analysis of social capital accumulation in connectivist MOOCs. Paper presented at the $5^{\text {th }}$ International Conference on Learning Analytics \& Knowledge (LAK'15), Poughkeepsie, New York.

Means, B. (2014). Learning online: What research tells us about whether, when and how. Routledge.

Means, B., Toyama, Y., Murphy, R., \& Bakia, M. (2013). The effectiveness of online and blended learning: A meta-analysis of the empirical literature. Teachers College Record, 115(3), 1-47.

Means, B., Toyama, Y., Murphy, R., Bakia, M., Jones, K., \& Planning, E. (2010). Evaluation of evidence-based practices in online learning: A meta-analysis and review of online learning studies. U.S Department of Education. Retrieved from https://eric.ed.gov/?id=ED505824

Moser-Mercer, B. (2014). MOOCs in fragile contexts. In U. Cress \& C. Delgado Kloos (Eds.), Proceedings of the European MOOC Stakeholder Summit 2014 (pp. 114-121). European Commission: eLearning Papers/Open Education Europa. Retrieved from http://www.emoocs2014.eu 
Murugesan, R., Nobes, A., \& Wild, J. (2017). A MOOC approach for training researchers in developing countries. Open Praxis, 9(1), 45-57. DOI: 10.5944/openpraxis.9.1.476

Petrides, L. (2002). Web-based technologies for distributed (or distance) learning: Creating learningcentered educational experiences in the higher education classroom. International Journal of Instructional Media, 29, 69-77.

Staker, H., \& Horn, M. B. (2012). Classifying K-12 blended learning. Innosight Institute. Retrieved from https://www.christenseninstitute.org/wp-content/uploads/2013/04/Classifying-K-12blended-learning.pdf

Stevenson, J., \& Willott, J. (2007). The aspiration and access to higher education of teenage refugees in the UK. Compare: A Journal of Comparative and International Education, 37(5), 671687. https://doi.org/10.1080/03057920701582624

Syed, M., \& Nelson, S. C. (2015). Guidelines for establishing reliability when coding narrative data. Emerging Adulthood, 3(6), 375-387. https://doi.org/10.1177/2167696815587648

United Nations. (1998). The Universal Declaration of Human Rights, 1948-1998. New York: United Nations Dept. of Public Information.

United Nations Educational, Scientific and Cultural Organization. (2015). Incheon declaration and framework for action education 2030: Towards inclusive and equitable quality education and lifelong learning for all. UNESCO. Retrieved from http://www.unesco.org/new/fileadmin/MULTIMEDIA/HQ/ED/ED/pdf/FFA Complet We b-ENG.pdf

United Nations High Commissioner for Refugees. (2016a). Left behind. Refugee education in crisis. UNHCR. Retrieved from https://www.unhcr.org/59b696f44.pdf

United Nations High Commissioner for Refugees. (2016b). Statistical yearbook. Geneva, Switzerland: United Nations High Commissioner for Refugees. Retrieved from https://www.unhcr.org/enus/statistics/country/5a8ee0387/unhcr-statistical-yearbook-2016-16th-edition.html

United Nations High Commissioner for Refugees. (2018). Turn the tide: Refugee education in crisis. UNCHR. Retrieved from https://www.unhcr.org/turnthetide/

Vonderwell, S. (2003). An examination of asynchronous communication experiences and perspectives of students in an online course: A case study. The Internet and Higher Education, 6(1), 7790. https://doi.org/10.1016/S1096-7516(02)00164-1

Wildavsky, B. (2017). Developing countries: Moocs in the developing world: Hope or hype? In G. Mihut, P. G. Altbach, \& H. de Wit (Eds.), Understanding global higher education (pp. 163165). Rotterdam, The Netherlands: SensePublishers. https://doi.org/10.1007/978-94-6351044-8 35 
Xu, D., \& Jaggars, S.S. (2014). Performance gaps between online and face-to-face courses: Differences across types of students and academic subject areas. Journal of Higher Education, 85(5), 633-659. DOI: 10.1080/00221546.2014.11777343

Zaka, P. (2013). A case study of blended teaching and learning in a New Zealand secondary school, using an ecological framework. Journal of Open, Flexible and Distance learning,17(1), 24-40.

Athabasca

University

(c) 